\title{
Gender Responsive Pedagogy for Teaching and Learning: The Practice in Ghana's Initial Teacher Education Programme
}

\author{
Eric Daniel Ananga \\ University of Education, Winneba, Winneba, Ghana \\ Email: edananga@gmail.com
}

How to cite this paper: Ananga, E. D. (2021). Gender Responsive Pedagogy for Teaching and Learning: The Practice in Ghana's Initial Teacher Education Programme. Creative Education, 12, 848-864. https://doi.org/10.4236/ce.2021.124061

Received: March 16, 2021

Accepted: April 22, 2021

Published: April 25, 2021

Copyright (C) 2021 by author(s) and Scientific Research Publishing Inc. This work is licensed under the Creative Commons Attribution International License (CC BY 4.0).

http://creativecommons.org/licenses/by/4.0/

\begin{abstract}
The use of instructional strategies that promote gender inclusion and sensitivity in initial teacher training is very important in the development of teachers. In this paper, the use of gender-responsive pedagogy in Ghana's initial teacher training programme is highlighted. Using data from baseline, midterm and end-line surveys, the paper addresses how tutors and mentors use gender responsive pedagogy and the changes that have occurred. The study adopted a mixed-method approach using lesson observations, interviews and a questionnaire to capture data from 310 participants (280 college tutors, 10 student teachers and 20 mentors) sampled from the 46 Colleges of Education in Ghana. The findings presented in this paper reveal that there has been significant improvement in the use of gender responsive pedagogy by the core subjects (English, Mathematics and Science) from the tutors sampled. Increases have been observed in both male and female tutors' demonstration of gender responsive pedagogy in their teaching. A similar increase has been found in the use of gender responsive mentoring strategies by mentors. The paper concludes by highlighting the implications of the findings for policy in the use of gender-sensitive pedagogy in Ghana's initial teacher training programme.
\end{abstract}

\section{Keywords}

Gender-Responsive Pedagogy, Methods, Student, Mentors and Tutors

\section{Introduction}

There is a significant body of evidence demonstrating that addressing inequalities in girls' education is an effective strategy for breaking the cycle of intergenerational poverty and for lifting girls and their families out of positions of margi- 
nalisation (GES, 2018). In Ghana, the importance of improving girls' access, retention and transition through the education system-from kindergarten through to tertiary education is widely acknowledged (MoE, 2018). As such, there has been a growing interest in and efforts at addressing gender related barriers in the education system. One major setback related to girls' access to education involves issues around girls' school enrolment (entry), survival and completion (MoE, 2018). In some communities and homes, girls tend to be engaged in extra house chores which sometimes impact on the time available for them to do education-related tasks. In addition, in school, it is sometimes the case that the culture, including materials and pedagogy used, tends to reinforce this kind of treatment towards girls. Several interventions have therefore been implemented to address gender biases, especially access issues (MoE, 2018). It is however critical that the challenges to girls' access, retention and completion are addressed simultaneously. The teacher has been identified as a critical factor in sustaining grade survival and completion of girls. It has been argued that the teacher's adoption of gender-responsive pedagogy is one way to ensure grade survival and completion for both boys and girls (MoE, 2018; GES, 2018). The school is particularly expected to create an enabling learning environment for girls. The use of gender sensitive pedagogy is therefore critical if the dominant gender bias within a patriarchal system is to be challenged.

\section{Literature Review}

There is a growing body of research that addresses the positioning of gender sensitive pedagogy as a means of change in university teaching (e.g. Kalonaityte, 2014; Bromseth \& Sörensdotter, 2012; Lykke, 2012). Commentators argue that the introduction of post-structural feminist thinking into teachers' education (Lenz Taguchi, 2005), appreciating the intersection of the norm in terms of nationality, sexuality and ethnicity, is critical to the holistic development of teachers. Globally, gender equality and equity have been identified as key issues in training teachers (Kreitz-Sandberg, 2016). According to UNESCO (2015), working with gender equality in teacher education encompasses a range of practices and policies including institutional culture, teacher attitudes, gender-responsive policies and, more importantly, designing gender sensitive pedagogy and instructional materials. These factors are critical in the design of a teacher training curriculum that is gender sensitive on a macro level, utilising management tools as well as evaluation strategies that are developed in consonance with gender sensitivity. Thus, teacher education institutions need to assess and develop a curriculum that encompasses gender sensitivity. For instance, UNESCO (2015: p. 60) indicates that:

The curricula adopted by TEIs [teacher education institutions] in preparing future teachers should be carefully revised. A quick look at the curricula set by many TEIs around the world ... reveals a grave short-coming regarding issues of gender equality. For example, students being prepared to become school- 
teachers are given courses on education theories, the psychology of learning, teaching methodologies and class management, evaluation and assessment, and one or two practicum courses. Nowhere can any emphasis on gender equality issues be seen ... This problem of omission needs to be addressed by curriculum designers of TEIs.

Introducing gender sensitive methodologies in the initial teacher training programme is crucial. Metz-Göckel (2012) advocates a gender dimension in university pedagogy so that ideas around gender mainstreaming and sensitivity can be integrated into university teaching (Kreitz-Sandberg, 2013). For gender sensitive teaching to be ensured, it is important to deliberately and strategically incorporate gender discourses into the pedagogy of teacher training programmes. This will encourage more gender equality and sensitive teaching (Kreitz-Sandberg, 2013; Bramberger, 2015) at the teacher preparation stage. These factors provide the basis for introducing gender-sensitive pedagogy in Ghana's teacher education programme. The need for teachers to ensure that girls and boys have equal opportunities in classroom activities is key. Gender equity in teaching and learning will be achieved by creating equal opportunities for boys and girls (Kahamba, Massawe, \& Kara, 2017). Creating the awareness among practicing teachers and pre-service teachers on treating girls and boys fairly during the instructional process is therefore very important (Abraha, Dagnew, \& Seifu, 2019). In the context of the present paper, gender responsive pedagogy refers to teaching and learning processes that pay attention to the specific learning needs of girls and boys respectively. The practice calls for teachers to take an all-encompassing gender approach to the processes of lesson planning, teaching, classroom management and performance. Gender responsive pedagogy has been introduced in Ghana's initial teacher education programme to prepare teachers for basic school posts (MoE 2017b; GES, 2018).

The main goal of the teacher education reform by Ghana's Ministry of Education is to build the capacity of tutors of Colleges of Education (CoEs) to train inspiring and motivational teachers. The National Teachers' Standards requires that every teacher should be able to ensure equity and inclusion in their classroom, with emphasis on girls and other vulnerable groups (MoE, 2017a). Moreover, in the National Teacher Education Curriculum Framework (MoE, 2017b) issues of equity and inclusion are applied to the five pillars of the curriculum framework $^{1}$. It is envisaged that all newly trained teachers will be equipped with the necessary pedagogical skills to support improved learning outcomes for all basic school children with emphasis on girls (MoE, 2017a, 2017b) Continuous professional development (CPD) materials have therefore been developed to build the capacity of $\mathrm{CoE}$ tutors in implementing gender responsive pedagogy during their lessons (2017b). After being taught with gender responsive pedagogy student teachers are being given the opportunity to apply and develop the ${ }^{1}$ The five pillars of the National Teacher Education Curriculum Framework are subject and curriculum knowledge, language and literacy, pedagogy and supported teaching in schools-practicum. 
knowledge skills and understanding during mentored school placements (internship) and expected to translate the knowledge, skills and competencies acquired when they are eventually posted to basic schools after completion of their programme.

Starting in 2015, CoE tutors have adopted gender responsive pedagogy in their lessons. According to the Gender handbook for practicing mentors (GES, 2018), certain actions and strategies are expected to be demonstrated in the classroom as a way of adopting gender responsive pedagogy. For instance, teachers are expected to:

- Give equal chance to females and males to ask and answer questions in class (and provide extra encouragement to girls who may lack confidence).

- Use participatory methods such as group work, debates and role play; and ensure the equal participation of females and males (including giving extra encouragement where needed).

- Pay attention to the positioning of females and males during group work and assign females leadership roles.

- Ensure that females have equal access to teaching and learning materials (TLMs) such as books, desks, etc., particularly if males are more assertive and take resources first.

- Be patient with females and males who may be shy or afraid to speak.

- Check to see if both females and males understand the lesson.

- Provide constructive and positive verbal feedback to both females and males in class.

The above points focus on gender responsive pedagogies and how they can be translated into practice in the classroom and made part of the school culture and climate.

Importantly, mentoring plays a critical role in the training of teachers as they (teachers) are considered to provide guidance to the teacher trainee. Mentoring in educational institutional especially in teacher training has increased speedily in transforming teaching and teacher education since the 1980s (Little \& Nelson, 1990). This has been helpful with the expectation that experienced teachers would not only perfect their professional practice but also guide novices to acquire new pedagogies apart from socializing professionally.

Mentoring is considered as a professional practice that allows for experienced and superintendence teachers to offer guidance to new teachers in areas such as syllabus preparation, moral guidance, co-curriculum activities, discipline management of pupils, information on school neighbourhood, schools policies, professional ethics, examination techniques, student counselling (Franke \& Dahlgren, 1996). A study conducted by Hawk (1986) revealed that involvement in mentoring programs enables teacher trainees to grow professionally. According to the study, mentoring compelled them to focus on and improve their own classroom teaching skills, enabled them to become aware of the necessity of educators to connect with one another.

From the argument above, it is expected that basic school teachers (Mentors), 
head teachers (Lead Mentors), student teachers (Mentees), CoE tutors and their management teams will be equipped with the essential competencies to improve their day-to day practice and ensure that the internship experience is also gender responsive (GES, 2018).

In this paper, changes since the adoption of the gender responsive approach are highlighted. The paper uses baseline, midterm and end-line evidence on how gender responsive pedagogy is being implemented during the training of student teachers. The evidence presented highlights progress made since the adoption of gender responsive pedagogy.

\section{Methodology}

As part of their training, student teachers are exposed to these actions and strategies during their training. It is important to monitor the implementation of gender responsive pedagogy focusing on the expectations listed. These expectations are measured on the scale: "not achieved", "partially achieved", "half achieved", and "fully achieved". Baseline, midterm and end-line data was therefore captured on the use of gender responsive pedagogy.

Using a mixed methods approach, the study was designed to observe changes that have occurred since $\mathrm{CoE}$ tutors begun implementing gender-responsive pedagogy. Baseline data was collected and compared with midterm and end-line data.

The survey approach employed a combination of different probability sampling strategies. The overall strategy may be described as stratified, multistage, systematic random sampling. To achieve a sample representative of the population, the random selection of sampling units was done proportionately to the size and in line with the pattern of the target population. The sample size assumed a varying sampling error for specific targets. A confidence level of $95 \%$ was adopted for tutors and mentors. To ensure a conservative sample size, a highly heterogeneous population with a maximum degree of variability of $50 \%$ was assumed. This was done to ensure that if the study is repeated using different participants from the same population, but selected in line with the sampling method, there will be a $95 \%$ certainty that observations made in future surveys will be within a range of $\pm 5 \%$ of observations made in the present survey. The same methodology for selecting the sample at baseline was employed throughout the four-year period 2015 to 2018 to ensure comparability of data and results.

\section{Participants}

There are 46 CoEs in Ghana located in 15 regions across the country. In each of the regions, there are education districts in which basic schools are located. Some basic schools located within the vicinity of CoEs have been designated as partnership schools and they offer the opportunity for close study. Student teachers from CoEs are expected to engage in an internship throughout the entire four-year period of their training programme. During the internship, stu- 
dent teachers are placed under the guidance of qualified professional teachers (mentors) in partnership schools to introduce them to teaching and its routines. This is to enable student teachers to acquire required professional skills and competencies. The period of internship provides student teachers with the opportunity to observe lessons of their mentors, practice peer and individual teaching and conduct small-scale research. The internship enables student teachers to reflect, practice and seek clarification about what they are learning in their colleges. As such, this study focused on three key participants. First, basic school-teachers, who are mentors, followed by student teachers - mentees - and lastly, college tutors who teach student teachers in CoEs. To find changes that have occurred in the implementation of gender-sensitive pedagogy, data was collected and compared from tutors, student teachers and mentors over time.

The population of the study therefore comprised tutors and student teachers of the $46 \mathrm{CoEs}$ as well as mentors in the partnership schools. From the $46 \mathrm{CoEs}$, a total of 20 colleges were sampled for the study. In each of the 20 sampled CoEs, 14 tutors were randomly sampled from those teaching core courses - English Language, Mathematics, and Science. In terms of student teachers, 10 (five males and five females) of them were randomly selected from the classes of the 14 tutors who were sampled, to triangulate the results from tutors. The partnership schools of the 20 sampled CoEs were also sampled to select mentors to participate in the study. Mentors were therefore selected from the districts where the 20 sampled CoEs are located. Twenty mentors who teach in the sampled basic schools from the districts where the CoEs are located were selected for participation in the study.

To facilitate the analysis of subgroups, CoEs were further stratified according to the sex composition of students (i.e., female-only CoEs, male-only CoEs and mixed-sex CoEs). As the survey sought to assess the gender dynamics within CoEs, a deliberate effort was made to select mixed-sex CoEs. In total, 2 female-only CoEs, and 18 mixed-sex CoEs were sampled.

\section{Procedure}

The selection of tutors took into consideration the levels at which they taught. Similar to the baseline and midterm approaches, the method of selection of tutors was stratified using random sampling where tutors were first categorised by the courses and the levels (100 and 200) at which they taught. They were then randomly selected. With regard to student teachers, 10 of them were randomly selected from the classrooms of the 14 teachers who had been sampled. To select the mentors, a list of mentees and the names of basic schools in the district where they had been assigned for internship was obtained from the respective CoEs. Out of this, a cross-section of schools emerged, and these schools were randomly selected for mentors' interviews.

To measure tutors' use of gender-responsive pedagogy, three main methods were employed to provide one composite data set: lesson observations, follow-up interviews with tutors; and self-administered questionnaires for 10 students of 
the observed tutors.

To triangulate data from tutors, the student teachers whose mentors had been sampled were interviewed with regard to the performance of mentors on the same actions and competencies. An ideal score was set for each action or competency. On the basis of the assessment by both mentors and mentees, a composite performance rating was computed. Information collected from the mentors was further triangulated with mentees who had been sampled. The following section discusses the results of the study.

The quantitative data and the interview data were transcribed. Questions focussed on tutors and student teacher's application of the three domains of the NTS as well as competencies. Data were analysed by collating participant responses into themes with processes of coding and recoding (Creswell, 2012).

\section{Results and Discussion}

\section{Demonstration of Gender-responsive Pedagogy by Tutors}

Tutors' use of gender-responsive pedagogy was assessed to explore the extent of equal treatment of female and male students with regard to questions, discussion, participation, encouragement, classroom leadership, etc., and usage of gender-responsive strategies with regard to challenging traditional gender roles in teaching and learning materials, examples, activities, etc.

The results in Table 1 show significant improvement for male and female tutors' demonstration of gender-responsive pedagogy in 2018. In 2015, few male tutors (1.8\%) demonstrated gender-responsive pedagogy. By 2017, 46\% of male tutors demonstrated the use of gender-responsive pedagogy in their teaching and by 2018 , more than half (68\%) of male tutors demonstrated gender-responsive pedagogy in their teaching. In the case of female tutors, improvements in the demonstration of gender responsive pedagogy were also observed, changing from $3.6 \%$ in 2015 to $64.4 \%$ in 2018 . These significant improvements in the adoption of gender responsive pedagogy were recorded for both female and male tutors teaching English Language, Mathematics, and Science. With gender sensitivity and equality mainstreamed into initial teacher education, the continuous adoption of gender responsive pedagogy by all tutors (both male and female) will encourage more gender equality and sensitive teaching (Kreitz-Sandberg, 2013; Bramberger, 2015) in basic schools.

Table 2 reveals tutors' demonstration of the use of gender-responsive pedagogy according by sex and level taught.

It was revealed that the proportion of male tutors who taught level 100 and 200 and who demonstrated gender-responsive pedagogy in their teaching increased significantly (68.9\%) by 2018 . The proportion of both female and male tutors who taught levels 100 and 200 and demonstrated gender-sensitivity instructional methods in their teaching also increased significantly between the years 2015 and 2018. This implies that over the period tutors had demonstrated the use of gender sensitive pedagogy in their teaching. Even though, it could be observed from Table 2 that male tutors demonstrated a higher use of gend- 
er-responsive pedagogy in their teaching, than their female counterparts, female tutors' demonstration of the gender sensitive pedagogy had equally increased impressively.

Table 3 presents data on competency scores of tutors on each assessment question for observing scores to identify areas of strengths and weaknesses. This was done to inform capacity-building programming for tutors.

Table 1. Tutors demonstrating gender-responsive pedagogy by sex and subject (\%).

\begin{tabular}{|c|c|c|c|c|}
\hline & Level & Baseline (Oct. 2015) & Midterm (Oct. 2017) & End-line (June 2018) \\
\hline \multirow[t]{6}{*}{ Male } & English & 4.7 & $45.8^{*}$ & $65.1^{\star}$ \\
\hline & Mathematics & 2.6 & $48.2^{\star}$ & $75.0^{*}$ \\
\hline & Science & 0.0 & $45.8^{*}$ & $65.8^{*}$ \\
\hline & Total & 1.8 & $46.7^{*}$ & $68.9^{*}$ \\
\hline & Total $(\mathrm{N})$ & 220 & 225 & 222 \\
\hline & English & 0.0 & $44.1^{*}$ & 57.1 \\
\hline \multirow[t]{4}{*}{ Female } & Mathematics & 11.1 & $50.0^{*}$ & 64.3 \\
\hline & Science & 5.9 & $55.6^{*}$ & $76.5^{*}$ \\
\hline & Total & 3.6 & $48.5^{*}$ & $64.4^{*}$ \\
\hline & Total (N) & 56 & 68 & 59 \\
\hline
\end{tabular}

${ }^{*} p \leq 0.05$.

Table 2. Tutors demonstrating gender-responsive pedagogy by sex and level taught (\%).

\begin{tabular}{ccccc}
\hline & Level & Baseline (Oct. 2015) & Midterm (Oct. 2017) & End-line (June 2018) \\
\hline \multirow{4}{*}{ Male } & 100 & 2.7 & $44.1^{*}$ & $72.0^{*}$ \\
& 200 & 0.0 & $49.5^{*}$ & $66.1^{\star}$ \\
& Total & 1.8 & $46.7^{*}$ & $68.9^{*}$ \\
& Total (N) & 220 & 225 & 222 \\
& 100 & 0.0 & $39.5^{*}$ & $63.0^{*}$ \\
& 200 & 13.0 & $64.0^{*}$ & 65.6 \\
& Female & 3.6 & $48.5^{*}$ & $64.4^{\star}$ \\
& Total & 56 & 68 & 59 \\
\hline
\end{tabular}

${ }^{\star} p \leq 0.05$.

Table 3. Raw competency scores for tutors.

\begin{tabular}{cccc}
\hline & $\begin{array}{c}\text { Baseline } \\
\text { (Oct. 2015) }\end{array}$ & $\begin{array}{c}\text { Midterm } \\
\text { (Oct. 2017) }\end{array}$ & $\begin{array}{c}\text { End-line } \\
\text { (June 2018) }\end{array}$ \\
\hline $\begin{array}{c}\text { The tutor uses gender-responsive strategies } \\
\text { to challenge gender roles and gender norms } \\
\begin{array}{c}\text { The tutor applies all teaching methods } \\
\text { equally to female and male students }\end{array}\end{array}$ & 1.9 & 25.2 & 91.1 \\
$\quad \begin{array}{c}\text { The tutor uses techniques } \\
\text { to address mixed abilities }\end{array}$ & 48.0 & 60.4 & 78.7 \\
\hline
\end{tabular}


From Table 3, the raw scores for tutors' use of gender-responsive pedagogy to challenge gender roles and norms from the baseline, midterm to the end-line were 1.9, 25.2 and 91.1 respectively. On the issue of tutors' application of all teaching methods equally to both female and male students, 48.0, 60.4 and 78.7 were recorded. Finally, tutors' use of techniques to address mixed abilities recorded 21.5, 45.8 and 69.4. All scores indicate an increase in the use of gender-responsive pedagogy in teaching over the period. To understand further, the details regarding the use of gender responsive pedagogy in teachers, interviews were conducted with some tutors.

During focus group discussion and interviews, most tutors mentioned that they had a good understanding of gender-responsive pedagogy and therefore applied them during lessons. They indicated that using gender-responsive pedagogy eliminated gender biases and stereotypes from the classroom. They emphasised that using gender responsive pedagogy provided equal opportunity for both male and female student teachers by ensuring that both were actively involved in the lesson. And where necessary, encourage female student teachers to take active part during the instructional process in to improve their performance. Some of their views include:

- "I believe tutors have a better understanding of what gender-sensitive teaching methods are about. It gives room for equal opportunity for both sexes in the classroom."

- "Gender-responsive pedagogy encourage students performing poorly in their academic work to now actively participate in class and improve."

- "I think most of us [tutors] have a better understanding of the gender-responsive pedagogy and also know how to apply them. The method helps all students to learn very well."

- "I think the gender-responsive pedagogy is an effective approach to helping students learn because its use has dismissed all the unnecessary arguments and unhealthy gender related competitions during lessons. There is no more 'males are like this and females are like that' in the system. Equal opportunity is given to all sexes to participate in everything that comes up."

- "I think gender-responsive pedagogy help students understand lessons well and pass their exams because the approach gives each student motivation and confidence to learn and make a difference. The change occurring because of gender responsive pedagogy is evident in the entire system. The current vice president of the student representative council is a female and it has never happened."

With regards to addressing the gender equity issues in schools, these narratives indicate that it is critical to ensure a well-balanced demonstration of gender responsive pedagogy by every tutor.

To understand how tutors apply the gender responsive pedagogy in their lessons, some focus group interviews were conducted where, several tutors mentioned that they desist from allowing students of one particular sex to dominate 
the class discussions during lessons. They indicated that they deliberately work to ensure that, they actively engage all students. One way they ensure this is to combine both female and male student teachers during group discussions and assignments and also, it is considered in their seating arrangements to avoid all males or all females sitting at one corner in the class. Nearly all tutors are mindful of their choice of words and language in the classroom. They revealed that when applying gender-responsive methods, they intentionally use "she or he" in sentences instead of "he or she."

Nearly all tutors who were engaged in this study, were of the view that gender-responsive pedagogy has helped curb male-dominance during lessons. They mentioned that another way they apply gender responsive pedagogy in the classroom is by ensuring that a female student teacher is often made a class leader, a group leader or put in charge of learning activities. Some of their comments include:

- "Yes, I have adequate knowledge of the gender-sensitive teaching methods. When grouping students in a class, we don't group them based on sex, but we allow both males and females to sit mix and together."

- "What we do is, for instance, in a class group work, we make sure we mix both males and females so that both sexes will be actively involved in whatever is going on in class."

- "The gender-responsive pedagogy influences learning and passing exams. It is common knowledge in this college that since the introduction of this approach, female students are becoming more confident, assertive and they do speak up in class. We have them in leadership roles. For example, we have ensured that some female students are class captains or prefects."

- "Nowadays, even our language in the classroom is more sensitive to gender. For instance, we normally use he or she (helshe), but now, we say she or he (shelhe). This is because we don't want to always put females second to males; women can also be first in anything they do."

- "I think gender-responsive pedagogy helps students to pass exams since the approach gives students the motivation and confidence to study together. Sometimes, when students study with the opposite sex, they learn well."

The responses above indicate a deliberate attempt by some tutors to incorporate gender-responsive pedagogy in the whole instructional process in the training of teachers. The deliberate use of gender sensitive language and involving more females to take up leadership roles during most instructional activities is important. The approach makes girls and boys feel involved in the instructional process as indicated and fairness will be enhanced as noted by Kahamba, Massawe and Kara (2017). This finding points to the emergence of the kind of change that institutions are likely to experience when gender responsive pedagogy is incorporated into pre-service teacher education and this is corroborated by some other studies (Kalonaityte, 2014; Bromseth \& Sörensdotter, 2012; Lykke, 2012). 
In spite of the fact that the use of gender responsive pedagogy is achieving much in the CoEs, as can be observed in this study, there are some challenges its implementation. For instance, some categories of tutors indicated that even though they have a good understanding of a gender-responsive pedagogy, they have some challenges in applying it entirely. It emerged that practising gender responsive pedagogy becomes redundant in single sex CoEs. Equally related, is the issue about class size and proportions of the opposite sex in the class which emerged as another problem. Tutors explained that some classes consist of over 100 student teachers with less than 10 percent being males or females. This according to them makes it difficult to adopt the usage of gender-responsive pedagogy in their teaching.

The issue of limited resources to support the practice of gender responsive pedagogy was another challenge. Tutors complained that their colleges lack available and appropriate TLMs that support gender-responsive pedagogy and content. They noted that there are some textbooks and reading materials that are not gender sensitive, thereby making demonstration of gender-responsive pedagogy during lessons extremely challenging. Comments from tutors to highlight some of challenges are noted below:

- "In situations where most of the class is one particular sex ... if you have two males in class and the rest are females, or vice versa. It is difficult to do gender balance in the class. In a home economics class, for example, there are only 2 male students in a class of 104 . That is my main challenge."

- "We lack appropriate TLMs which will assist us in applying the gender-responsive pedagogy. Some of the textbooks are old and contain examples which portray single-sex dominance."

- "Most female students are not supportive of females in leadership roles. When we intentionally make female students class captains, some fellow females resist because they don't appreciate it if another woman should rule over them. They prefer males rather than females."

- The types of textbooks that we have in the college are also not gender friendly and we don't control that. When your style of teaching and examples you give are contradicted by the textbooks, it is a problem. So, it would be helpful if T-TEL can support in this regard so that the publishers can also take gender-responsiveness into consideration when they are publishing textbooks.

The emerging finding regarding the challenges is an indication that there are some tutors who have not entirely grasped the concept of gender responsive pedagogy and its applications. Their understanding in some cases suggests that they interpreted the approach to having equal numbers in the class instead of giving or creating equal opportunities for all learners at the same time. Also, the issue of textbook that are not gender-sensitive requires the innovativeness of the tutor in selecting materials (improvisation) to use, which is one of the prescriptions when adopting gender responsive pedagogy.

In addition to how tutors were adopting gender responsive pedagogy, mentors 
were also assessed to explore the extent to which their mentoring approach is supportive and in line with what student teachers were learning in their CoEs.

\section{Demonstration of Gender-responsive Pedagogy by Mentors}

Given the significant roles mentors play in providing learning support to mentees, their knowledge and application of gender-responsive pedagogy is very relevant for initial teacher preparation. The role of mentors is critical in guiding student teachers to build their teaching skills and competencies in real life classroom situations (clinical approach). Mentors act as role models who support the development of student teacher's confidence, give them a first-hand experience of professional practice through structured training and coaching. Mentors have been trained and exposed to use gender-responsive pedagogy to equip them to guide mentees (student teachers). In assessing the use of gender-responsive pedagogical practices of mentors, they were interviewed with respect to several specific actions and competencies that were expected of them. The gender-sensitive mentoring domains that were measured include, 1) support provided to mentees at the beginning of internship, 2) support provided to mentees during practicums, 3) extra support provided for female mentees and 4) competencies mentees improved under mentorship during their practicums.

From the key informant interviews and focused group discussions, most mentors mentioned that they have a good understanding of what gender-responsive pedagogy is about. Mentors indicated that applying gender-sensitive approach is important because it helps to address biases and stereotypes that certain roles or activities reserved only for males or females entail. The findings from mentors confirm tutors' findings that gender-responsive pedagogy is effective in helping all pupils to learn and pass exams. The results in Table 4 show a significant improvement for both male and female mentors' use of gender responsive pedagogy during mentoring between the years 2015 and 2018 .

The analysis also explored performance across mentors' subject areas. The results reveal that both male and female mentors who teach all subjects showed a significant improvement over the period observed. In all cases, there have been significant improvements in the scores on mentors use of gender responsive pedagogy during their mentoring and coaching sessions.

As part of the evaluation, mentors were asked to provide some detail regarding how they provide support to mentees to enable them adopt gender-responsive pedagogy during lesson delivery. Insight from the focus groups and key informant interviews revealed that nearly all the mentors indicated that the mentoring strategies include the use of gender-responsive pedagogy in their teaching. They gave examples such as instructing mentees to be mindful of the seating arrangements for boys and girls in the class to ensure that pupils are mixed during lessons, showing mentees how to distribute questions fairly to both sexes and the use of gender-sensitive examples during lesson delivery to mentees to see. In explaining how they provide the support, they said: 
Table 4. Proportion of male and female mentors using gender-sensitive mentoring strategies by subject (\%).

\begin{tabular}{|c|c|c|c|c|}
\hline & Subjects & $\begin{array}{l}\text { Baseline } \\
\text { (Oct. 2015) }\end{array}$ & $\begin{array}{l}\text { Midterm } \\
\text { (May 2017) }\end{array}$ & $\begin{array}{l}\text { End-line } \\
\text { (June 2018) }\end{array}$ \\
\hline \multirow{7}{*}{ Male } & English & 3.9 & $12.5^{*}$ & 16.0 \\
\hline & Mathematics & 0.0 & $9.8^{*}$ & 15.2 \\
\hline & Science & 0.0 & $12.5^{\star}$ & 15.6 \\
\hline & All subjects & 0.0 & 7.5 & $41.0^{*}$ \\
\hline & Specific subjects ${ }^{2}$ & 1.4 & $15.8^{*}$ & $26.1^{*}$ \\
\hline & Total & 1.2 & $12.2^{\star}$ & $27.2^{*}$ \\
\hline & Total N & 165 & 213 & 191 \\
\hline \multirow{7}{*}{ Female } & English & 2.7 & 0.0 & $15.4^{*}$ \\
\hline & Mathematics & 0.0 & $9.1^{*}$ & $17.7^{\star}$ \\
\hline & Science & 0.0 & $9.1^{*}$ & $18.2^{*}$ \\
\hline & All subjects & 0.0 & $10.3^{*}$ & $28.2^{*}$ \\
\hline & Specific subjects & 2.6 & $12.9^{*}$ & 5.0 \\
\hline & Total & 2.0 & $10.7^{\star}$ & $23.0^{*}$ \\
\hline & Total N & 203 & 197 & 209 \\
\hline
\end{tabular}

${ }^{*} p \leq 0.05$.

- “... before my mentee begins a lesson, I advise them to rearrange the seating arrangement in the class before beginning the lesson. I also provide support by encouraging the female pupils to be actively involved in the lesson."

- "I encourage my mentee to concentrate on the female pupils, especially in the mathematics class because the girls will not tell you that they do not understand but rather nod if you ask the whole class if everyone understands."

- "I support my mentees by inspecting their lesson notes to ensure that the content is not gender-biased, especially when it contains practical examples. At times, when mentees have TLMs, I help them to ensure that their TLMs are gender sensitive."

- "During lesson delivery, there are certain periods that a teacher must arouse and sustain the interest of children due to fatigue or loss of concentration. This is one flair that mentees are now don't have experience in, so I use that opportunity to be present in the class to support them by equally engaging both girls and boys in a series of activities to arouse their interest."

- "I team up with the mentees to teach. At certain times. I support them to use gender-responsive pedagogical approach to engage students in competitions. During such learning activities, the class can become chaotic and disorga-

${ }^{2}$ Specific subjects are the elective courses which include, History, Geography, Social Studies, French, Ghanaian Language, Physical Education, Music, Technical and Vocational Education subjects (Visual Arts, Home Economics, Agriculture, etc.). 
nised due to over excitement. So, I support them also to control the class."

These excerpts show mentors' approach to supporting mentees during internship. Thus, the role of mentors in supporting mentees is critical as corroborated by Franke and Dahlgren (1996), that mentoring as a professional practice allows for experienced and superintendent teachers to offer guidance to new teachers. They present vivid illustrations of how mentors and mentees relate during the instructional process. The evidence presented reflects the success achieved in implementing gender responsive pedagogy by tutors.

However, some challenges have been mentioned by mentors regarding the use of gender responsive pedagogy during their practice. Some mentors mentioned that the textbooks they use at the basic schools are not gender sensitive. Like tutors, mentors explained that textbooks contained examples of stereotype gender roles and activities and they are biased. Some mentors suggested that some pupils are still affected by how society and culture have classified what a male or female can and cannot do. Like tutors, certain category of mentors mentioned that it is sometimes challenging to involve both sexes in learning activities; in particular, they mentioned that some female pupils perceive certain subjects such as mathematics and science to the reserve for boys and that those subjects are difficult. They said:

- "I think that some of our cultural beliefs which suggest that a woman's place is in the kitchen are still having an effect on some children, in the sense that no matter what you will do, some girls think they cannot rise above boys. They are reluctant to be participatory in class. As for a subject like maths, the issue is worse."

- “... girls are scared of mathematics. They perceive it to be difficult for them but easy for boys. So, when I try to balance questions and activities in a mathematics class, the girls become reluctant to participate. As Teachers, we always try to encourage the girls not to think like that because they are equal to boys."

- "My challenge is that, in my class, only a few of girls can read. But when it comes to the male pupils, a lot of them can read. As a local language teacher, I try to apply the gender-responsive pedagogy by pairing the students, one boy one girl, but I still have a challenge of getting the females to read."

- "In my class, the challenge that I face is with leadership roles. When I purposefully choose a female pupil as a team leader, the other girls in addition to the boys raise their voice in objection. Even the females think that they should have male leaders. You will do your best to explain to them the importance of allowing females to lead a team, but they will still object to it. I always try to encourage females to be leaders during group tasks in class but it seems they have been taught in their homes that males should assume leadership roles."

These excerpts are evidence that there still remains some barriers to overcome in the implementation of gender responsive pedagogy. For instance, the back- 
ground and household beliefs and practices around gender poses a critical challenge. As mentors try to inculcate the use of gender responsive pedagogy in mentees so that they can in turn practice it in the future, the existence of such contextual challenges pose a threat to the extent to which gender-responsive pedagogy can fully achieve its objective. Changing such beliefs that children carry from home to school will require some time.

\section{Conclusion}

This study looked at gender-responsive pedagogy in Ghana's initial teacher training programme. From the findings, the paper concludes that $\mathrm{CoE}$ tutors increasingly used gender-responsive pedagogy for teaching the core subjects such as English Language, Mathematics and Science. The proportion of both female and male tutors who taught at levels 100 and 200 and demonstrated gender-responsive pedagogy in their teaching also increased over the period.

On the issue of performance across the subject areas by mentors, the study found that both genders used gender-sensitive mentoring strategies. These findings have implications for policy in many ways. For instance, the use of gender-responsive pedagogy should be encouraged across all subject areas in the curriculum to deepen its practice among tutors and mentors. It is necessary that mentors and tutors be trained regularly on the use of gender-responsive pedagogy in their teaching so that they will be able to assist and guide student-teachers to use them as well. In the continuous capacity building programme organised by Ghana Education Service and the Ministry of Education, Mentors and Tutors should be mandated to use gender-responsive pedagogy in their teaching by consciously including its use in the basic school and CoE curriculum.

One area that requires serious revision is the textbooks in use in the schools. It is important that the textbooks the government approved for use in schools are reviewed in line with the use of gender responsive teaching and learning in mind. Also, teachers' guides and training manuals to guide teachers on how to teach the various subjects in the curriculum should have gender-responsive pedagogy approach integrated. It is worth mentioning that the issue of tutors misconceptions over aspects of gender-responsive approaches needs addressing and the need to prepare student teachers to address challenges arising from cultural bias and stereotypes which pupils bring from home is critical.

\section{Acknowledgements}

This study formed part of T-TELs internal monitoring in partnership with the Ministry of Education with funding from DfID. The author is grateful to all those at the various CoEs and partnership schools where data were collected. Thanks also go to all the T-TEL staff who contributed in various ways in the different components of the programme. Finally, a big thanks to all the tutors, students and mentors in all $20 \mathrm{CoEs}$ from whom data were gathered. 


\section{Conflicts of Interest}

The author declares no conflicts of interest regarding the publication of this paper.

\section{References}

Abraha, M., Dagnew, A., \& Seifu, A. (2019). Gender Responsive Pedagogy: Practices, Challenges \& Opportunities-A Case of Secondary Schools of North Wollo Zone, Ethiopia. Journal of Education, Society and Behavioral Science, 30, 1-17. https://doi.org/10.9734/jesbs/2019/v30i330128

Bramberger, A. (2015). PädagogInnenprofession und Geschlecht: Gender Inclusion. Wien: New Academic Press.

Bromseth, J., \& Sörensdotter, R. (2012). Normkritisk pedagogik: En mölighet att förÄndra undervisningen. In A. Lundberg, \& A. Werner (Eds.), Genusvetenskap-ens pedagogik och didaktik (pp. 45-59). Göteborg: Nationella sekretariatet för genusforskning.

Creswell, J. W. (2012). Educational Research: Planning, Conducting, and Evaluating Quantitative and Qualitative Research (4th ed.). Boston, MA: Pearson.

Franke, A., \& Dahlgren, L. O. (1996). Conceptions of Mentoring: An Empirical Study of Conceptions of Mentoring during School-Based Teacher Education. Teaching and Teacher Education, 12, 627-641. https://doi.org/10.1016/S0742-051X(96)00004-2

GES (2018). The Gender Handbook for Teaching Practice Mentors: A Guide for Implementing Gender Responsive Pedagogy, Policies and Practices during Teaching Practice. Accra: GES.

Hawk, P. (1986). Beginning Teacher Programmes: Benefits for the Experienced Educator in Recruiting and Inducting Quality Personnel for Schools. Action in Teacher Education, 8, 59-64. https://doi.org/10.1080/01626620.1986.10519321

Kahamba, J. S., Massawe, F. A., \& Kara, E. S. (2017). Awareness and Practice of Gender Responsive Pedagogy in Higher Learning Institutions: The Case of Sokoine University of Agriculture, Tanzania. Journal of Education, Humanities and Science, 6, 1-16.

Kalonaityte, V. (2014). Normkritisk pedagogik-För den högre utbildningen. Stockholm: Studentlitteratur.

Kreitz-Sandberg, S. (2013). Gender Inclusion and Horizontal Gender Segregation: Stakeholders' Strategies and Dilemmas in Swedish Teachers' Education. Gender and Education, 25, 444-465. https://doi.org/10.1080/09540253.2013.772566

Kreitz-Sandberg, S. (2016). Improving Pedagogical Practices through Gender Inclusion: Examples from University Programmes for Teachers in Preschools and Extended Education. International Journal for Research on Extended Education, 4, 71-91.

https://doi.org/10.3224/ijree.v4i2.25782

Lenz Taguchi, H. (2005). Getting Personal: How Early Childhood Teacher Education Troubles Students' and Teacher Educators' Identities Regarding Subjectivity and Feminism. Contemporary Issues in Early Childhood, 6, 244-255.

https://doi.org/10.2304/ciec.2005.6.3.5

Little, J. W., \& Nelson, L. (Eds.) (1990). Leader's Guide to Mentor Training. San Francisco, CA: Far West Laboratory.

Lykke, N. (2012). Intersektionell genuspedagogik. In A. Lundberg, \& A. Werner (Eds.), Genusvetenskapens pedagogik och didaktik (pp. 28-35). Göteborg: Nationella sekretariatet för genusforskning. 
Metz-Göckel, S. (2012). Genderdimensionen in der Hochschuldidaktik-Forschung. In M. Kampshoff, \& C. Wiepcke (Eds.), Handbuch Geschlechterforschung und Fachdidaktik (pp. 317-330). Wiesbaden: Springer VS. https://doi.org/10.1007/978-3-531-18984-0 23 MoE (2017a). National Teachers Standards' for Ghana: Guidelines. Accra: MoE.

MoE (2017b). National Teacher Education Curriculum Framework: the Essential Elements of Initial Teachers Education. Accra: MoE.

MoE (2018). Education Strategic Plan 208-2030. Accra: MoE.

UNESCO (2015). A Guide for Gender Equality in Teacher Education Policy and Practices. Paris: UNESCO. 